Article

\title{
Pro-Science, Anti-Science and Neutral Science in Online Videos on Climate Change, Vaccines and Nanotechnology
}

\author{
M. Carmen Erviti ${ }^{1, *}$, Mónica Codina ${ }^{2}$ and Bienvenido León ${ }^{2}$ \\ ${ }^{1}$ School of Management Assistants, University of Navarra, 31009 Pamplona, Spain; E-Mail: mcerviti@unav.es \\ ${ }^{2}$ School of Communication, University of Navarra, 31009 Pamplona, Spain; E-Mails: mcodina@unav.es (M.C.), \\ bleon@unav.es (B.L.)
}

* Corresponding author

Submitted: 20 February 2020 | Accepted: 19 May 2020 | Published: 26 June 2020

\begin{abstract}
Online video has become a relevant tool to disseminate scientific information to the public. However, in this arena, science coexists with non-scientific or pseudoscientific beliefs that can influence people's knowledge, attitudes, and behavior. Our research sets out to find empirical evidence of the representation of pro-science, anti-science and neutral stances in online videos. From a search on Google videos, we conducted content analysis of a sample of videos about climate change, vaccines and nanotechnology $(n=826)$. Results indicate that a search through Google videos provides a relatively small representation of videos with an anti-science stance, which can be regarded as positive, given the high potential influence of this search engine in spreading scientific information among the public. Our research also provides empirical evidence of the fact that an anti-science stance is more frequent in user-generated content than in videos disseminated by other types of producers.
\end{abstract}

\section{Keywords}

climate change; Google; nanotechnology; science communication; user-generated content; vaccines; video production

\section{Issue}

This article is part of the issue "Health and Science Controversies in the Digital World: News, Mis/Disinformation and Public Engagement" edited by An Nguyen (Bournemouth University, UK) and Daniel Catalan (University Carlos III of Madrid, Spain).

(C) 2020 by the authors; licensee Cogitatio (Lisbon, Portugal). This article is licensed under a Creative Commons Attribution 4.0 International License (CC BY).

\section{Introduction}

In recent years, terminology seeking to classify messages that are favorable or contrary to established scientific knowledge have proliferated. In relation to anti-science stance messages, terms such as 'misinformation,' 'disinformation,' 'fake news' and 'denialism' are applied. On the other hand, 'science advocacy' and 'pro-science' are employed to promote a stronger role of science in society. Neither positive nor negative, 'neutral science' and related words are simply descriptive and explanatory. It is not our intention to discuss or delimit these terms. Prior work has been done by other authors in this regard (e.g., Gerasimova, 2018; Lazer et al., 2018; Scheufele \& Krause, 2019).
In this article, we use the terms 'pro-science,' 'antiscience,' and 'neutral science' broadly, covering all related words. We use 'pro-science' to express active support for established scientific knowledge; 'neutral science' as an expression neither in support or against established scientific knowledge, and 'anti-science' as contrary to established scientific knowledge.

Our goal is to better understand how much proscience, anti-science and neutral science messages circulate in videos returned by Google search results and who exactly are the people responsible for producing these videos in relation to three selected topics: climate change, vaccines, and nanotechnology. Finally, we analyze scientists' voices in a sample of videos. 


\section{Literature Review}

\subsection{Pro-Science vs. Anti-Science}

Science coexists with non-scientific or pseudoscientific beliefs that influence people's knowledge, attitudes, and behavior. In the Internet era, citizens' search for scientific information based on preexisting beliefs and values (Yeo, Cacciatore, \& Scheufele, 2015), plus the difficulty of recognizing inaccurate information (Lazer et al., 2018), may result in an increasing number of misinformed citizens.

According to Schmid and Betsch (2019), anti-science messages resort to false experts, appeal to conspiracies, ask for the impossible (e.g., 100\% vaccine safety), create false dilemmas or biased selections of data. In these cases, the authors point out that, in order to avoid misleading information, it is necessary to fight back with immediate responses. We argue that this can be applied to respond to anti-science with pro-science claims.

Non-scientific and beliefs do not arise from all scientific topics. Consequently, there are some topics that cause hardly any anti-science messages to be produced while other topics provoke manifold and widely spread anti-science messages. It is precisely those scientific issues polarizing society that generate a large number of anti-science and pro-science messages. Climate change is a perfect example.

There is overwhelming scientific consensus on climate change (Carlton, Perry-Hill, Huber, \& Prokopy, 2015; Cook et al., 2013). However, the discussion about its very existence, causes and consequences, remains within the purview of non-scientific forums. Petersen, Vincent and Westerling (2019) found that the visibility in press articles of those who deny climate change was $49 \%$ higher than that of those who believe in it. Even in The New York Times, The Guardian or The Wall Street Journal, contrarians were cited slightly more often than those who represented scientific consensus. The role of media in the journalistic coverage of climate change has been studied from the perspective of balance, a journalistic routine that seeks neutrality regarding controversial issues, but one that in this case has led to greater visibility of anti-science positions (Boykoff, 2007).

In online media, during the US presidential campaign and subsequent election, Donald Trump was the top influencer on global warming, significantly increasing the presence of skeptical discourse on climate change (Swain, 2017). Conversely, the youth movement initiated by Greta Thunberg, namely Fridays for Future, has contributed to a call to action to address climate change in worldwide media (Boykoff et al., 2019).

Although less present in the global political arena, vaccines are yet another scientific topic that produces a vast number of both anti-science and pro-science messages. Vaccines have largely been shown to be effective. Nevertheless, some parents still refuse to have their children vaccinated, basing their decision on different rea- sons: religious/philosophical or personal beliefs, safety concerns, and a desire for further information (McKee \& Bohannon, 2016).

The most emblematic case of anti-science stance in the field of vaccines was that of the measles-mumpsrubella vaccine. A study published in the late 1990s hypothesizing a link between measles-mumps-rubella vaccination and autism (Wakefield et al., 1998) contributed to a significant boost of the anti-vaccination movement. Though the medical journal that published this article later retracted, the idea had already penetrated many people's minds through the media, which for many years have continued to spread this supposed relationship between measles-mumps-rubella, vaccination and autism (Dixon \& Clarke, 2013). Indeed, Hoffman et al. (2019, p. 2216) have recently found that "social media outlets may facilitate anti-vaccination connections and organization by facilitating the diffusion of centuries old arguments and techniques."

Many papers analyze anti-vaccine movements, but the literature on pro-vaccine activism is sparse. In fact, a variety of pro-vaccine activism groups have been shown to focus, to a greater or lesser extent, and in diverse ways, on the political and media debate (Vanderslott, 2019).

Pro- or anti-nanotechnology movements exist but they do not have a prominent social impact. Little evidence is found of political or religious polarization regarding nanotechnology (Drummond \& Fischhoff, 2017). This young science is controversial on issues such as stem-cell research and genetic modification of human beings; impacts on human life, family and social structures; or the creation of artificial intelligences (Sandler, 2009; Scheufele \& Lewenstein, 2005). However, in the public sphere, nanotechnology is currently not as questioned as climate change or vaccines (Erviti, Azevedo, \& Codina, 2018). Fragmented and ambiguous media portrayals of nanotechnology may actually mitigate its risks (Boholm \& Larsson, 2019).

\subsection{Online Videos}

One of the types of content that grows faster in Internet traffic is video (Cisco, 2019). Editing a scientific video implies a greater effort than publishing a post or a tweet, and can also imply greater intentionality; besides, its high potential impact has made video a key tool to distribute scientific information to the public (León \& Bourk, 2018). The problem is that the dynamics of online circulation of videos may be favoring misinformation, even more so when, in topics such as climate change, deniers and skeptics participate more actively than pro-science people in social media (Arlt, Hoppe, Schmitt, De Silva-Schmidt, \& Brüggemann, 2018).

The video platform most analyzed by academics is YouTube. It was created in 2005 and it was purchased by Google the following year, 2006. Unfortunately, different studies on YouTube's recommendation algorithm indicate that it promotes what we call anti-science. For 
the selected topics for this research, we find the following conclusions:

In relation to climate change, YouTube videos support worldviews that to a large extent oppose scientific consensus (Allgaier, 2019). This platform promotes and recommends denialist and anti-scientific videos, including conspiracies and false theories about climate change. Some of these videos accumulate hundreds of thousands of views (Avaaz, 2020).

Vaccine videos have been more frequently studied than climate change videos. Venkatraman, Garg, and Kumar $(2015$, p. 1422) claimed that "online communities with greater freedom of speech lead to a dominance of anti-vaccine voices," so the level of freedom of online speech correlates with the level of misinformation about vaccines. According to their results, support for a link between vaccines and autism is most prominent on YouTube, followed by Google search results. Other authors confirm this view with their studies on YouTube videos: Song and Gruzd (2017), for example, concluded that $65.02 \%$ of the videos were anti-vaccine, $20.87 \%$ were pro-vaccine, and $14.11 \%$ were neutral. Ekram, Debiec, Pumper, and Moreno (2019) discovered that the anti-vaccine ideology was prevalent in video content and commentary, containing erroneous and incomplete information. Moreover, anti-immunization content is generally favored over pro-immunization content (Yiannakoulias, Slavik, \& Chase, 2019).

There are no published studies regarding nanotechnology on YouTube. In any case, the good news is that YouTube video platform recommendations leading to content with conspiracy theories have been reduced by $40 \%$ as of April 2019, due to changes in its algorithm (Faddoul, Chaslot, \& Farid, 2020).

While YouTube amplifies "sensational content because of its tendency to generate more engagement" (Faddoul et al., 2020, p. 1), Google is a different search engine that prioritizes quality (DiSilvestro, 2017) and tries to avoid misinformation (Del Vicario et al., 2016). Unlike YouTube, Google is not a video platform, so searches on Google videos display links to websites which algorithm detects a hosted video. In the case of YouTube, search results directly show videos. For these reasons, the use of YouTube and Google is usually for different purposes: Google is most often used as a tool for finding information, YouTube for entertainment. However, many Google search results link to YouTube videos (DiSilvestro, 2017), somehow unsettling this canonical divide.

Previous studies on the results of video searches on Google have not been found. Regarding the scientific topics for our present undertaking, there are only a few precedents about vaccine webpages. A study carried out in 2002 on Google concluded that $43 \%$ of the first 10 websites in search results were anti-vaccination (Davies, Chapman, \& Leask, 2002). More recently, Arif et al. (2018) found that most vaccine webpages returned in Google searches in 6 different languages were pro-vaccine $(43 \%-70 \%$, with diverging results depending on the language).
Various forms of scientific content dissemination have been widely studied, however extant literature on promoters and drivers of this information is limited. In digital communication, the term 'user' designates a natural or legal person using a computer or network service. Growing access to information and communication technologies has facilitated the transformation of some users into producers. We focus on the different producers that create and disseminate online scientific content: professionals and amateurs, organizations and individual users. In this sense, the work of Burgess and Green (2013) on YouTube suggests that all users have become 'participants' in the same scenario, but the differences between content producers persists and varies depending on their range and motivations. Delving further into this aspect is vital, so this article provides a classification of video producers.

\subsection{Scientists' Voices}

Traditionally, two kinds of video content have been distinguished: user-generated content (UGC) and professionally generated content (PGC). UGC used to be amateur but widespread on social media, while PGC occurred mainly in video marketing or media communication, in other words, it was mostly employed to create institutional content (Kim, 2012). Currently, there are amateur users called 'YouTubers' who have become professionalized, while some professionally-produced content imitate amateurism (León \& Bourk, 2018). A previous study indicates that UGC deals with scientific controversy more often than PGC (Erviti et al., 2018), which could be a predictor that this type of users might be more likely to produce anti-science videos.

Beyond the differentiations between UGC and PGC, it is interesting to note in what proportion some actors, such as scientific institutions, media, business, or citizens are producers of scientific videos. Besides, it might lead to improving the existing knowledge about the presence of scientific voices in online videos in relation to proscience and anti-science attitudes.

Previously, we explained the prevalence of antiscience voices in press articles on climate change. In Petersen et al. (2019), the voices of 386 prominent contrarians (academics, scientists, politicians, and business people) gained far more visibility than the 386 highest cited climate scientists. The authors "demonstrate why climate scientists should increasingly exert their authority in scientific and public discourse, and why professional journalists and editors should adjust the disproportionate attention given to contrarians" (p. 1).

On social media, scientists should also be prominent voices, but only $2 \%$ of Twitter content and $3 \%$ of Facebook posts on climate change come from scientific work (Grouverman, Kollanyi, Howard, Barash, \& Lederer, 2018). As producers of online video on this issue, scientific institutions are seemingly overcome by the media (Erviti, 2018). Meanwhile, calls are made for scientists 
to become climate activists (Gardner \& Wordley, 2019) and the role of academic climate advocacy is discussed (Boykoff \& Oonk, 2018).

Regarding vaccines, Orr and Baram-Tsabari (2018) concluded that the virtual dialogue on the polio vaccination debate on Facebook had become more political than scientific. Finally, the few studies about the online conversation on nanotechnology conclude that the most active users appear to be individuals rather than the official channels of scientific institutions, although the retweets of news from Nature, Scientific American, NASA, etc., stand out (Veltri, 2012). Even Runge et al. (2013, p. 1) discovered that, in the US, tweets were "more likely to originate from states with a federally funded National Nanotechnology Initiative center or network."

\section{Research Questions and Hypotheses}

The research questions of this research are the following:

RQ1. To what extent do scientific videos obtained through the Google search engine have a neutral orientation, or are positioned in favor or against established scientific knowledge?

RQ2. Which video producers are more likely to launch neutral messages, for, or against established scientific knowledge?

RQ3. To what extent are the voices of scientists used in neutral videos, in favor, and against established scientific knowledge?

In addition, three hypotheses are formulated in relation to RQ2 and RQ3. RQ1 seeks a first approximation to the positioning of science videos, so we do not have a previous hypothesis.

H1. In our classification of producers, the positioning against established scientific knowledge is greater in videos produced by users (UGC) than in videos produced by other actors.

H2. Neutrality is more frequent in videos produced by news media than in videos produced by other actors.

H3. The presence of scientists is more frequent in videos positioned in favor of established scientific knowledge than in those against it.

$\mathrm{H} 1$ is based on previous research that provides conclusions to support this hypothesis (Song \& Gruzd, 2017; Venkatraman et al., 2015). H2 is supported by the traditional journalistic principles of objectivity and balance (e.g., Boykoff, 2007). Finally, regarding $\mathrm{H} 3$, since the majority of the scientific community supports the existence of an anthropogenic climate change, the efficiency of vaccination and the benefits of nanotechnology, we assume that those videos in favor of established scientific knowledge could portray more scientists than those videos against science.

\section{Methodology}

The sample of videos that we selected for this research comes from a comprehensive research project that has produced a number of results, some of which were published in a collective work (León \& Bourk, 2018).

This project conducted content analysis of online videos about three topics: climate change, vaccines, and nanotechnology. The selection of these three scientific topics is related to contemporary disciplinesin Environment, Health, and Technology-receiving public and academic attention, however noticing marked differences among them as explained in the introductory section.

The sample was selected by searching for the English terms 'climate change,' 'vaccines' and 'nanotechnology' on the videos section of Google. This search engine was used because it was the most frequently tool employed by users, and it would therefore yield videos with the largest potential projection.

The search was conducted in Spain on October 16, 2015. An incognito window was opened on Google to conduct anonymous searches, all cookies were deactivated and the cache memory cleaned, factors which might have interfered with the reliability of the results. The system returned 600 webpage links for each search term, which were conditioned by the search engine algorithm. The results were filtered, excluding those videos that were not accessible due to technical problems, did not cover the subject matter as the main topic, or were repeated. Videos that exceeded 20 minutes in length were also excluded due to limited resources for their analysis, due to operational reasons (e.g., including videos over 20 minutes in the sample would have made coding analysis unfeasible). Following this filtering process, our sample resulted in 300 videos on climate change, 268 on vaccines, and 258 on nanotechnology ( $n=826)$.

An initial coding proposal was discussed in three meetings of the research team, resulting in a code book that was designed to carry out the analysis. Before starting this process, a pre-test of the questionnaire was carried out, in which two coders applied the code to $5 \%$ of the sample, aimed at detecting problems of comprehension and making the necessary adjustments. Following the testing phase, the final code book was reached. Once the coding of the videos was completed, a reliability test was carried out. The test consisted in taking $10 \%$ of the coded sample and comparing whether the coding carried out by the coders matched. The agreement between the two coders that performed the task was higher than $85 \%$ for each variable used in this study.

Table 1 lists the variables and questions of the code book. 
Table 1. Code book

\begin{tabular}{|c|c|}
\hline Topic & $\begin{array}{l}\text { Climate change; } \\
\text { Vaccines; } \\
\text { Nanotechnology. }\end{array}$ \\
\hline Video title/Host webpage & (title/name of the host webpage). \\
\hline Type of author & $\begin{array}{l}\text { Scientific institution (research/technology center, university, etc.); } \\
\text { Company (excluding media companies); } \\
\text { Media (newspaper, radio, television, digital media, etc.; } \\
\text { Non-scientific institution (NGO/Association); } \\
\text { UGC, understood as non-institutional videos on platforms like YouTube; } \\
\text { Other. }\end{array}$ \\
\hline $\begin{array}{l}\text { Does the video take a position in } \\
\text { favor (pro-science) or against (anti-science) } \\
\text { established scientific knowledge? }\end{array}$ & $\begin{array}{l}\text { No (neutral); } \\
\text { Yes. }\end{array}$ \\
\hline In case it does, it takes a position: & $\begin{array}{l}\text { Against established scientific knowledge (anti-science). E.g., against } \\
\text { vaccination/nanotechnology or denying anthropogenic climate change; } \\
\text { According to established scientific knowledge (pro-science). }\end{array}$ \\
\hline Do scientists speak in the video? & $\begin{array}{l}\text { No; } \\
\text { Yes; } \\
\text { Unclear whether they are scientists or not. }\end{array}$ \\
\hline
\end{tabular}

The data and information collected were quantitatively analyzed and the three hypotheses of the study statistically contrasted through a chi square test.

\section{Results}

\subsection{Research Question 1}

Most videos in the sample (55.4\%) take a pro-science stance, while $40.4 \%$ are neutral, and only $4.1 \%$ take a stance against science. The pro-science or neutral positions are predominant in the three topics of our study. Climate change is shown as the topic in which the proscience stance is most frequent $(68.3 \%)$ and least neutral (28.3\%).

Vaccines turn out to be the scientific issue that generates most controversy, with $8.2 \%$ of videos positioned against established scientific knowledge. Climate change follows those results, with $3.3 \%$ of videos against established scientific knowledge. Finally, nanotechnology is by far the least controversial $(0.78 \%$ of videos against) and often addressed from a neutral stance (49.6\%; Table 2).

\subsection{Research Question 2}

Results indicate the predominance of online and offline media as producers of video with scientific content $(52.7 \%)$. Behind the mass media, we find scientific institutions (15.7\%), UGC (12.1\%), non-scientific institutions (10\%), companies (6\%), and other producers (3.2\%). We tested whether these frequencies are significantly different and they are on the whole $\left(X^{2}(5)=113.41\right.$; $p<0.001)$, but not compared with scientific institutions and UGC $\left(X^{2}(1)=1.96 ; p>0.05\right)$, or UGC and nonscientific institutions $\left(X^{2}=1.58 ; p>0.05\right)$.

Surprisingly, non-scientific institutions are the producer that stands out in favor of established scientific knowledge (71\%), even ahead of scientific institutions (65.3\%; Table 3). Examples of non-scientific institutions are the World Wildlife Fund (The Arctic: Our First Sign of Climate Change | Ocean Today), the TED

Table 2. Positioning of videos.

\begin{tabular}{lccc}
\hline & Pro-science & Anti-science & Neutral \\
\hline Climate change $(\%, \mathrm{n}=300)$ & 68.3 & 3.3 & 28.3 \\
Vaccines $(\%, \mathrm{n}=268)$ & 46.6 & 8.2 & 45.1 \\
Nanotechnology $(\%, \mathrm{n}=258)$ & 49.6 & 0.7 & 49.6 \\
Total $(\%, \mathrm{n}=826)$ & 55.4 & 4.1 & 40.4 \\
\hline
\end{tabular}


Table 3. Video producers.

\begin{tabular}{lccc}
\hline & Pro-science & Neutral & Anti-science \\
\hline Media (\%, $\mathrm{n}=436)$ & 54.3 & 42.2 & 3.4 \\
Scientific institution $(\%, \mathrm{n}=130)$ & 65.3 & 33 & 1.5 \\
Non-scientific institution $(\%, \mathrm{n}=83)$ & 71 & 25.3 & 3.6 \\
User (UGC; \%, $\mathrm{n}=100)$ & 46 & 41 & 13 \\
Company (\%, $\mathrm{n}=50)$ & 44 & 56 & 0 \\
Other/unknown (\%, $\mathrm{n}=27)$ & 33.3 & 62.9 & 3.7 \\
Total $(\%, \mathrm{n}=826)$ & $55.4 \%$ & $40.4 \%$ & $4.1 \%$ \\
$\mathrm{H} 1: \mathrm{X}^{2}(1)=22.75 ; \mathrm{p}<0.001$ & & & \\
$\mathrm{H} 2: \mathrm{X}^{2}(1)=1.19 ; \mathrm{p}>0.05$ & & & \\
\hline
\end{tabular}

Foundation (The Reality of Climate Change | David Puttnam, TEDxDublin, 2014) and the UN (Our Future I Narrated by Morgan Freeman, 2014).

Media take a pro-science stance much more frequently than a neutral stance, which situates communication companies in an intermediate position (54.3\%). Meanwhile, less than $50 \%$ of videos produced by users (46\%), companies (44\%) and other producers (33.3\%) are in favor of established scientific knowledge. In the last two cases, producers tend to offer neutral videos: companies, $56 \%$ of videos; other producers, $62.96 \%$. If we disregard the media, the weighted percentage of neutral videos is $32 \%$.

The most outstanding percentage of videos positioned against established scientific knowledge is the one corresponding to users (13\%). This is relevant because it clearly exceeds the categories of other producers (3.7\%), non-scientific institutions (3.6\%) and media (3.4\%). If we disregard UGC, the weighted percentage of anti-science videos is $2.8 \%$.

On the other hand, scientific institutions hardly offer videos that contradict science (1.5\%). Companies in the sample did not produce videos against established scientific knowledge but mostly neutral videos (apart from the 'others' category).

Next, we checked whether hypotheses 1 and 2 are fulfilled. The contrast of hypotheses through the chi square test confirms $\mathrm{H} 1\left(\mathrm{X}^{2}(1)=22.75 ; \mathrm{p}<0.001\right.$; the parameters 'users' and 'videos against' are interdependent). Therefore, it is confirmed that, in the videos produced by users, the percentage against established scientific knowledge is higher than the percentage against science in the videos by the rest of producers.

Our second hypothesis $(\mathrm{H} 2)$ was that, among the videos produced by media, the percentage of neutral videos would be higher than among the videos by other producers. However, this hypothesis is not confirmed by the chi square test $\left(X^{2}(1)=1.19 ; p>0.05\right)$. Therefore, it cannot be stated that the media take a more neutral stance than the rest of producers.

Among 34 videos that took an anti-science stance, $18(52.9 \%)$ were linked to YouTube and one of them to Facebook. The remaining 15 were linked to several online news media-either legacy media like The Guardian or $A B C$ News, or newcomers like The Huffington Post. Although these media are not detractors of science, in some cases they produced videos giving exclusive voice to those who denied established science (e.g., "US climate change deniers," 2015) and provided links to videos of other anti-science producers (e.g., "Sarah Palin compares climate change "hysteria' to eugenics," Relly, 2014).

Who are, then, the dissonant voices in our sample? In climate change videos, we find several American conservative politicians, like Sarah Palin, Ben Carson and Carly Fiorina, as well as the Prime Minister of India, ultranationalist Narendra Modi. The list also includes several controversial people, like the author of The Skeptical Environmentalist (2001), Bjorn Lomborg, and the nuclear industry consultant and former president of Greenpeace Canada, Patrick Moore. The denialist think tank Heartland Institute is also included in the sample.

As far as vaccine videos are concerned, dissonant voices came from candidates for the Republican nomination to the Presidency of the US, Donald Trump and Rand Paul; YouTube channels (Experimental Vaccines; Hear this well; Autism media channel); Facebook celebrity Dr. Tenpenny on vaccines and current events; Irish broadcaster and politician Paschal Mooney; and radio show host and conspiracy theorist Alex Jones.

Only two videos take an anti-nanotechnology stance and no relevant voices from public opinion are included.

\subsection{Research Question 3}

Voices of scientists are more frequently represented in videos about vaccines (53\%), followed by videos on nanotechnology $(46.5 \%)$ and climate change $(27 \%)$. As seen in Table 4, scientists are more likely to be present in proscience videos (46.5\%) than anti-science clips (35.3\%) or neutral ones (35.3\%). Similarly, videos without scientists make up $53.5 \%$ of pro-science videos, compared with $64.7 \%$ of anti-science and neutral ones. However, the differences are not statistically significant $\left(X^{2}(1)=1.60\right.$; $p>0.05)$. Therefore, $\mathrm{H} 3$ is not supported: scientists have no statistically significantly stronger presence in videos favoring established scientific knowledge than in videos against or neutral about such knowledge. 
Table 4. Scientists' voices.

\begin{tabular}{lccr}
\hline & $\begin{array}{c}\text { Pro-science } \\
(\%, \mathrm{n}=458)\end{array}$ & $\begin{array}{c}\text { Anti-science } \\
(\%, \mathrm{n}=34)\end{array}$ & $\begin{array}{c}\text { Neutral } \\
(\%, \mathrm{n}=334)\end{array}$ \\
\hline Videos with scientists & 46.5 & 35.3 & 35.3 \\
Videos without scientists & 53.5 & 64.7 & 64.7 \\
\hline $\mathrm{H} 3: \mathrm{X}^{2}(1)=1.60 ; \mathrm{p}>0.05$ & & & \\
\hline
\end{tabular}

\section{Discussion}

We have asked to what extent scientific videos obtained through the Google search engine have a neutral orientation, or are positioned in favor or against established scientific knowledge. Our results show that the videos obtained through the Google search engine are mainly positioned in favor of established scientific knowledge or display a neutral stance. Only a few videos were found to question the established scientific knowledge on climate change, vaccines, and nanotechnology. This result does not necessarily mean that this is also the case for the whole Internet universe, since it is known that the algorithms that the Google search engine uses to numerically assign the relevance of the documents that are indexed (called PageRank) give priority to videos from relevant sources, thus potentially minimizing the presence of videos from sources that take an anti-science stance.

Our results contradict those of other studies that found a more prominent representation of videos with an anti-science stance on YouTube, as explained in the introductory section (Allgaier, 2019; Avaaz, 2020; Ekram et al., 2019; Song \& Gruzd, 2017; Venkatraman et al., 2015; Yiannakoulias et al., 2019). The differences in search results on Google and YouTube have been empirically verified in the present study. This indicates that Google is a safer search engine when it comes to finding reliable information, while YouTube video recommendations remain controversial.

We asked which video producers are more likely to launch neutral messages, for, or against established scientific knowledge. The videos produced by non-scientific institutions are more frequently in favor of pro-science than those produced by other types of producers, including scientific institutions. This may be explained by considering that among non-scientific institutions there are national and international institutions, as well as NGOs that support science. Researchers have discussed the role of NGOs in science communication (e.g., Doyle, 2007, on climate change; Vanderslott, 2019, on vaccines). Here empirical evidence of its weight in pro-science videos is provided.

Some videos with an anti-science stance have been produced by news media, as part of their information about opinions of outsiders (groups or individuals). In such cases, it cannot be stated that the media play against established scientific knowledge, since they fulfill the informative mission of offering a varied set of opin- ions on a given topic, trying to strike a balance among several sources.

In addition, the context in which the aforementioned videos were published should be taken into account. Even though we only analyzed the video content, in many cases videos are part of a news site where each video is contextualized with accompanying text. Moreover, some other videos had previously been broadcast on television, where a presenter introduces the video providing some contextual information.

In general, results indicate that the media are proscience. It cannot be stated that they take a more neutral stance than the rest of video producers $(\mathrm{H} 2)$ and the number of anti-science videos produced by media is low. However, research on climate change conducted by Petersen et al. (2019) found that, even in prestigious news media like The New York Times, The Guardian and The Wall Street Journal, 'climate skeptics' were cited slightly more often than voices supporting scientific consensus. This raises the question whether points of view against scientific consensus are used too often, perhaps because they are regarded by journalists as being more interesting for the public.

Only one of the three hypotheses that we posed has been corroborated: In the videos produced by users (UGC), the positioning against science is greater than in the videos produced by other actors (H1). Most UGC videos were distributed via YouTube, which confirms previous research linking this platform and anti-science videos (Allgaier, 2019; Song \& Gruzd, 2017; Venkatraman et al., 2015).

Quite surprisingly, $\mathrm{H} 3$ has not been demonstrated. Contrary to what we hypothesized, scientists are evenly represented both in videos with a pro-science stance and in videos with an anti-science stance. The reason might be that the sample of anti-science videos was small. In any case, it is likely that detractors include scientists in their videos to provide an image of epistemological authority.

\section{Conclusions and Limitations}

Our research has provided the first empirical evidence showing that the characteristics of videos obtained through the Google search engine may differ significantly from those of YouTube. In particular, we have demonstrated that, compared to YouTube videos, the videos obtained through the Google search engine display a differ- 
ent position regarding the support of established scientific knowledge.

Furthermore, among the videos obtained through the Google search engine, an anti-science stance is more frequent in UGC than in other types of content. Our research has also demonstrated that non-scientific institutions play a notable role in the diffusion of reliable scientific information, since the videos they produce often support established scientific knowledge.

The relatively small representation of videos with an anti-science stance in the results provided by Google videos can be regarded as positive. After all, this search engine provides results that usually support established science, thus minimizing the possible impact of misinformation that results from spreading information that contradicts established scientific knowledge.

We have also confirmed that the neutral stance is no more frequent in videos produced by news media when compared to other producers. In general, the media tend to support established scientific knowledge, though still lending space to the representation of anti-science videos. Even if this result is consistent with the journalistic principle of balance, it can have a worrying potential contribution to the public's misinformation about certain scientific disciplines.

Since science detractors frequently give voice to scientists in videos that contradict established scientific knowledge, it is advisable for science advocates to counter that trend and reinforce the presentation of scientists' voices in their productions as well. It is also recommended that scientists who support established scientific knowledge should play a more active role in spreading science through online video, which has become a most relevant source of scientific information for the public.

The results of our research are admittedly limited to a specific search through Google videos. However, we consider that it is possible to generalize some relevant conclusions, based also on the contrast of our results with previous studies. It provides a starting point for future research on science communication through online videos.

\section{Acknowledgments}

This work was funded by the Spanish Ministry of Economy and Competitiveness (COS 2013-45301-P). Special thanks are due to the reviewers of Media and Communication for their invaluable suggestions.

\section{Conflict of Interests}

The authors declare no conflict of interests.

\section{Supplementary Material}

Supplementary material for this article is available online in the format provided by the author (unedited).

\section{References}

Allgaier, J. (2019). Science and environmental communication on YouTube: Strategically distorted communications in online videos on climate change and climate engineering. Frontiers in Communication, 4. https://doi.org/10.3389/fcomm.2019.00036

Arif, N., Al-Jefri, M., Bizzi, I. H., Perano, G. B., Goldman, M., Haq, I., . . \& \& Ghezzi, P. (2018). Fake news or weak science? Visibility and characterization of antivaccine webpages returned by Google in different languages and countries. Frontiers in Immunology, 9, 1215.

Arlt, D., Hoppe, I., Schmitt, J. B., De Silva-Schmidt, F., \& Brüggemann, M. (2018). Climate engagement in a digital age: Exploring the drivers of participation in climate discourse online in the context of COP21. Environmental Communication, 12(1), 84-98.

Avaaz. (2020, January 15). Why is YouTube broadcasting climate misinformation to millions? (Avaaz Report). New York, NY: Avaaz. Retrieved from https://avaazimages.avaaz.org/youtube_climate_ misinformation_report.pdf

Boholm, A., \& Larsson, S. (2019). What is the problem? A literature review on challenges facing the communication of nanotechnology to the public. Journal of Nanoparticle Research, 21(86), 1-21.

Boykoff, M. (2007). Flogging a dead norm? Newspaper coverage of anthropogenic climate change in the United States and United Kingdom from 2003 to 2006. Area, 39(4), 470-481.

Boykoff, M., Aoyagi, M., Benham, A., Daly, M., Doi, K., Fernández-Reyes, R., . . . \& Ytterstad, A. (2019). World newspaper coverage of climate change or global warming, 2004-2019. Boulder, CO: University of Colorado.

Boykoff, M., \& Oonk, D. (2018). Evaluating the perils and promises of academic climate advocacy. Climatic Change. https://doi.org/10.1007/s10584-0182339-3

Burgess, J., \& Green, J. (2013). YouTube: Online video and participatory culture. Cambridge: Polity.

Carlton, J. S., Perry-Hill, R., Huber, M., \& Prokopy, L. S. (2015). The climate change consensus extends beyond climate scientists. Environmental Research Letters, 10(9). https://doi.org/10.1088/1748-9326/10/ 9/094025

Cisco. (2019, February 27). Cisco visual networking Index: Forecast and trends, 2017-2022 (White Paper Document ID 1551296909190103). San José, CA: Cisco. Retrieved from https://www.cisco.com/c/en/us/ solutions/collateral/executive-perspectives/annualInternet-report/white-paper-c11-741490.html

Cook, J., Nuccitelli, D., Green, S. A., Richardson, M., Winkler, B., Painting, R., .. . \& Skuce, A. (2013). Quantifying the consensus on anthropogenic global warming in the scientific literature. Environmental Research Letters, 8(2). https://doi.org/10.1088/1748-9326/8/ $2 / 024024$ 
Davies, P., Chapman, S., \& Leask, J. (2002). Antivaccination activists on the world wide web. Archives of Disease in Childhood, 87(1), 22-26.

Del Vicario, M., Bessi, A., Zollo, F., Petroni, F., Scala, A., Caldarelli, G., . . . \& Quattrociocchi, W. (2016). The spreading of misinformation online. Proceedings of the National Academy of Sciences, 113(3), 554-559.

DiSilvestro, A. (2017, October 31). Google videos vs. YouTube: Which is the best video search engine? Search Engine Watch. Retrieved from https://www. www.searchenginewatch.com/2017/10/31/Google videos-vs-youtube-which-is-the-best-video-searchengine

Dixon, G., \& Clarke, C. (2013). The effect of falsely balanced reporting of the autism-vaccine controversy on vaccine safety perceptions and behavioral intentions. Health Education Research, 28(2), 352-359.

Doyle, J. (2007). Picturing the clima(c)tic: Greenpeace and the representational politics of climate change communication. Science as Culture, 16(2), 129-150.

Drummond, C., \& Fischhoff, B. (2017). Individuals with greater science literacy and education have more polarized beliefs on controversial science topics. Proceedings of the National Academy of Sciences, 114(36), 9587-9592.

Ekram, S., Debiec, K. E., Pumper, M. A., \& Moreno, M. A. (2019). Content and commentary: HPV vaccine and YouTube. Journal of Pediatric and Adolescent Gynecology, 32(2), 153-157.

Erviti, M. C. (2018). Producing science online video. In B. León \& M. Bourk (Eds.), Communicating science and technology through online video (pp. 28-40). Abingdon: Routledge.

Erviti, M. C., Azevedo, J., \& Codina, M. (2018). When science becomes controversial. In B. León \& $\mathrm{M}$. Bourk (Eds), Communicating science and technology through online video (pp. 41-54). Abingdon: Routledge.

Faddoul, M., Chaslot, G., \& Farid, H. (2020). A longitudinal analysis of YouTube's promotion of conspiracy videos. Cornell University. Retrieved from https:// arxiv.org/abs/2003.03318

Gardner, C. J., \& Wordley, C. F. (2019). Scientists must act on our own warnings to humanity. Nature Ecology \& Evolution, 3(9), 1271-1272.

Gerasimova, K. (2018). Advocacy science: Explaining the term with case studies from biotechnology. Science and Engineering Ethics, 24(2), 455-477.

Grouverman, A., Kollanyi, B., Howard, P., Barash, V., \& Lederer, T. (2018). Climate change consensus and skepticism: Mapping climate change dialogue on Twitter and Facebook (Data Memo 2018.6). Oxford: Project on Computational Propaganda.

Hoffman, B. L., Felter, E. M., Chu, K. H., Shensa, A., Hermann, C., Wolynn, T., . . \& \& Primack, B. A. (2019). It's not all about autism: The emerging landscape of antivaccination sentiment on Facebook. Vaccine, 37(16), 2216-2223.
Kim, J. (2012). The institutionalization of YouTube: From user-generated content to professionally generated content. Media, Culture \& Society, 34(1), 53-67.

Lazer, D. M., Baum, M. A., Benkler, Y., Berinsky, A. J., Greenhill, K. M., Menczer, F., . . . \& Schudson, M. (2018). The science of fake news. Science, 359(6380), 1094-1096.

León, B., \& Bourk, M. (Eds.). (2018). Communicating science and technology through online video: Researching a new media phenomenon. Abingdon: Routledge.

Lomborg, B. (2001). The skeptical environmentalist. Cambridge: Cambridge University Press.

McKee, C., \& Bohannon, K. (2016). Exploring the reasons behind parental refusal of vaccines. The Journal of Pediatric Pharmacology and Therapeutics, 21(2), 104-109.

Orr, D., \& Baram-Tsabari, A. (2018). Science and politics in the polio vaccination debate on Facebook: $A$ mixed-methods approach to public engagement in a science-based dialogue. Journal of Microbiology \& Biology Education, 19(1).

Petersen, A. M., Vincent, E. M., \& Westerling, A. L. (2019). Discrepancy in scientific authority and media visibility of climate change scientists and contrarians. $\mathrm{Na}$ ture Communications, 10(1), 1-14.

Relly, M. (2014, October 27). Sarah Palin compares climate change 'hysteria' to eugenics. The Huffington Post. Retrieved from https://www.huffpost.com/ entry/sarah-palin-climate-change-eugenics_n_ 6057934?guccounter=1

Runge, K. K., Yeo, S. K., Cacciatore, M., Scheufele, D. A., Brossard, D., Xenos, M., .. . \& Liang, X. (2013). Tweeting nano: How public discourses about nanotechnology develop in social media environments. Journal of Nanoparticle Research, 15(1), 2-11.

Sandler, R. (2009). Nanotechnology: The social and ethical issues (Technical Report). Washington, DC: Woodrow Wilson International Center for Scholars, Project on Emerging Technologies.

Scheufele, D. A., \& Krause, N. M. (2019). Science audiences, misinformation, and fake news. Proceedings of the National Academy of Sciences, 116(16), 7662-7669.

Scheufele, D. A., \& Lewenstein, B. V. (2005). The public and nanotechnology: How citizens make sense of emerging technologies. Journal of Nanoparticle Research, 7(6), 659-667.

Schmid, P., \& Betsch, C. (2019). Effective strategies for rebutting science denialism in public discussions. $\mathrm{Na}$ ture Human Behaviour, 3(9), 931-939.

Song, M. Y. J., \& Gruzd, A. (2017, July). Examining sentiments and popularity of pro-and anti-vaccination videos on YouTube. In Proceedings of the 8th international conference on social media \& society (pp. 1-8). Toronto: ACM.

Swain, J. (2017). Mapped the climate change conversation on Twitter in 2016. Carbon Brief. Retrieved from https://www.carbonbrief.org/mapped-the-climatechange-conversation-on-twitter-in-2016 
TEDxDublin. (2014, December 1). The reality of climate change [Video file]. Retrieved from https://www. youtube.com/watch?v=SBjtO-OtbKU

UN. (2014, September 23). Our future [Video file]. Retrieved from https://www.youtube.com/watch?v= 8YQlaOldDU8

US climate change deniers lambast the Pope over his environment encyclical [Video file]. (2015, June 12). Retrieved from https://www.theguardian.com/ environment/video/2015/jun/12/us-climatechange-deniers-pope-environment-encyclical-video

Vanderslott, S. (2019). Exploring the meaning of provaccine activism across two countries. Social Science \& Medicine, 222, 59-66.

Veltri, G. A. (2012). Microblogging and nanotweets: Nanotechnology on Twitter. Public Understanding of Science, 22(7), 832-849.

Venkatraman, A., Garg, N., \& Kumar, N. (2015). Greater freedom of speech on Web 2.0 correlates with dominance of views linking vaccines to autism. Vaccine,
33(12), 1422-1425.

Wakefield, A. J., Murch, S. H., Anthony, A., Linnell, J., Casson, D. M., Malik, M., . . . \& Valentine, A. (1998). Retracted: Ileal-lymphoid-nodular hyperplasia, nonspecific colitis, and pervasive developmental disorder in children. The Lancet, 351, 637-41.

World Wildlife Fund. (n.d.). The Arctic: Our first sign of climate change [Video file]. Retrieved from https:// oceantoday.noaa.gov/firstsignofclimatechange

Yeo, S. K., Cacciatore, M. A., \& Scheufele, D. A. (2015). News selectivity and beyond: Motivated reasoning in a changing media environment. In O. Jandura, T. Petersen, C. Mothes, \& A. M. Schielicke (Eds.), Publizistik und gesellschaftliche Verantwortung [Journalism and social responsibility] (pp. 83-104). Wiesbaden: Springer.

Yiannakoulias, N., Slavik, C. E., \& Chase, M. (2019). Expressions of pro-and anti-vaccine sentiment on YouTube. Vaccine, 37(15), 2057-2064.

\section{About the Authors}

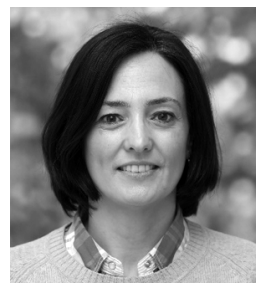

M. Carmen Erviti holds a PhD in Communication. She is Associate Professor of Corporate Communication at the School of Management Assistants, University of Navarra (Spain). She is a member of the Research Group on Science Communication at this University. Her research focuses on the study of Science Communication.

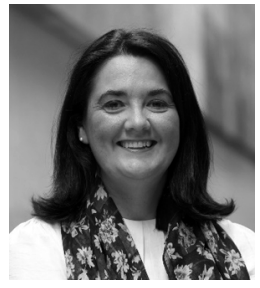

Mónica Codina holds a PhD in Philosophy. She is Associate Professor of Communication Ethics at the School of Communication, University of Navarra (Spain). She is a member of the Research Group on Science Communication at this University. Her research focuses on the study of Communication Ethics, attending to both its philosophical foundation and its practical application.

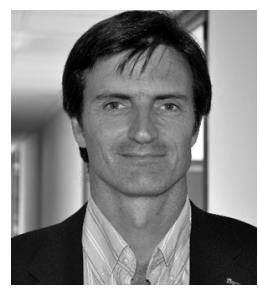

Bienvenido León is Associate Professor of Science Journalism and Television Production at the School of Communication, University of Navarra (Spain). He has published over 80 peer-reviewed articles and 23 books as author or editor, including Communicating Science and Technology through Online Video: Researching a New Media Phenomenon (Routledge, 2018) and Science on Television: The Narrative of Scientific Documentary (Pantaneto Press, 2007). He is the Founder and Coordinator of the Research Group on Science Communication at the University of Navarra. 